\title{
Dioctyltin and tributyltin detection at trace levels in water and beverages by capillary gas chromatography with flame photometric detection
}

Received: 20 July 1998 / Revised: 26 August 1998 / Accepted: 28 August1998

\begin{abstract}
A simple chromatographic procedure has been developed for the sensitive determination of dioctyltin and tributyltin compounds in water and beverages. Dioctyltin and tributyltin react with $\mathrm{NaBH}_{4}$ at $\mathrm{pH} 5$ to produce volatile hydrides which can be quantitatively extracted into $\mathrm{CH}_{2} \mathrm{Cl}_{2}$. The corresponding dioctyltin hydride derivative is identified by HPLC-ES-MS and measured by flame photometric detection using the quartz surface-induced tin emission. Detection limits of less than $0.7 \mathrm{pg}$ of tributyltin and $10 \mathrm{pg}$ of dioctyltin were achieved. Results showed that up to $9.5 \mathrm{ng} / \mathrm{mL}$ levels of dioctyltin were present in beverages.
\end{abstract}

\section{Introduction}

Dioctyltin compounds as stabilizers for PVC for food and beverage packings have been widely used in the recent two decades $[1,2]$. In many ways these compounds are slowly transferred, degraded and released to the environment. Owing to their significant environmental impact, deep concern has been caused regarding the risk of these stabilizer migrating from PVC products into beverage, food and finally into our body. Consequently, it is necessary to obtain more information on the contamination levels and the environmental risk connected with dioctyltin products. In recent years, several publications dealt with the quantitative determination of dioctyltin in environmental and biological samples, including HPLC [3], GC-FID [4], GC-AAS [5] and GC-FPD [6]. However, most of these methods lack sufficient sensitivity and precision in analyzing real samples at low concentrations. In this paper, we propose a simple and reliable method by gas chromatography with flame photometric detection us-

G. B. Jiang $(\varangle) \cdot$ F. Z. Xu $\cdot$ F. J. Zhang

Research Center for Eco-Environmental Sciences,

Chinese Academy of Sciences, P.O.Box 2871,

Beijing, 100085, P.R. China

e-mail: gbjiang@mail.rcees.ac.cn ing quartz surface-induced tin emission for the quantitative determination of dioctyltin and tributyltin compounds at trace levels in water and beverages. Parameters such as derivatization, separation, identification and detection conditions were investigated.

\section{Experimental}

\subsection{GC-FPD and HPLC-ES-MS}

A modified GC-9AM gas chromatograph (Shimadzu, Japan) equipped with a laboratory-made flame photometric detector (FPD) using quartz surface-induced luminescence was used throughout the experiment. The measurement was carried out by using a 394-nm interference filter. The FPD configuration and its analytical figure of merits were described previously [7, 8]. Chromatograms were recorded on an SC-1100 data processing system. A $10 \mathrm{~m} \times 0.25 \mathrm{~mm}$ i.d. capillary column coated with a film of $0.12 \mu \mathrm{m}$ CP-Sil-5 CB (Chrompack, Middelburg, Netherlands) was used. The optimized chromatographic conditions are given in Table 1.

A Fisons VG-platform mass spectrometer equipped with an electrospray ionization source was used for the identification of the hydride generated diocyltin compound. The temperature of the ES

Table 1 GC-FPD operating conditions

\begin{tabular}{ll}
\hline Parameters & Conditions \\
\hline Injection port temperature & $220^{\circ} \mathrm{C}$ \\
Injection volume & $1 \mu \mathrm{L}$ \\
Column & Chrompack CP-Sil-5CB $10 \mathrm{~m} \times$ \\
& $0.25 \mathrm{~mm}$ i.d. capillary column \\
& coated with a film of $0.12 \mu \mathrm{m}$ \\
Carrier gas & High purity nitrogen \\
Column head pressure & $4.6 \mathrm{~kg} / \mathrm{cm}^{2}$ \\
Oven temperature programming & Initial $70^{\circ} \mathrm{C}$ for $1 \mathrm{~min}, \mathrm{ramp}$ at \\
& $15^{\circ} \mathrm{C} / \mathrm{min}$ final $150^{\circ} \mathrm{C}$ and \\
& $\mathrm{kept} \mathrm{for} 3$ min \\
Detector temperature & $160{ }^{\circ} \mathrm{C}$ \\
PMT & $\mathrm{RP}-268$ \\
Hydrogen flow rate & $400 \mathrm{~mL} / \mathrm{min}$ \\
Air flow rate & $120 \mathrm{~mL} / \mathrm{min}$ \\
Detector purge & Nitrogen at $55 \mathrm{~mL} / \mathrm{min}$ \\
Data recording & $\mathrm{SC}-1100$
\end{tabular}


ionization source was maintained at $60^{\circ} \mathrm{C}$. The voltages of the ES capillary and the HV lens were kept at $3.29 \mathrm{KV}$ and $0.20 \mathrm{KV}$ during the whole operation. The measurement was performed in the negative ion mode.

\subsection{Reagents and standards}

Tributyltin chloride (TBT, 98.6\%), tetrabutyltin (TeBT, 99.44\%) and dioctyltin oxide (DOT, pure) were obtained from M\&T Chemical Inc., USA. Tetrabutyltin (TeBT) was directly weighed and dissolved in $\mathrm{CH}_{2} \mathrm{Cl}_{2}$ to obtain a concentration of $1 \mathrm{mg} / \mathrm{mL}$ (as $\mathrm{Sn}$ ) and diluted with distilled water to prepare standard solutions. Tributyltin chloride (TBT) was weighed and dissolved in methanol to a concentration of $1 \mathrm{mg} / \mathrm{mL}$ (as $\mathrm{Sn}$ ) as a stock solution; working standard solutions were diluted with distilled water. Since dioctyltin oxide (DOT) was difficult to dissolve in $\mathrm{CH}_{2} \mathrm{Cl}_{2}$ or methanol, the oxide was weighed and dissolved in $12 \mathrm{M} \mathrm{HCl}$ in a water bath, which was temperature controlled at $40^{\circ} \mathrm{C}$, when the white solid completely turned into liquid state, the solution was diluted and made up exactly to $100 \mathrm{~mL}$ with methanol.

Buffer solutions of HAc-NaAc were prepared by dissolving suitable amounts of $1 \mathrm{M} \mathrm{HAc}$ and $\mathrm{NaAc}$. The $\mathrm{pH}$-values of this series buffer solutions were measured by an acidimeter (pHS-2, Shanghai Second Analytical Instruments Factory, China). Another series of buffer solutions was made from $\mathrm{Na}_{2} \mathrm{HPO}_{4} \cdot 12 \mathrm{H}_{2} \mathrm{O}(1 \mathrm{M})$ and citric acid (1 M).

\subsection{Analytical procedure}

For a routine operation, $20 \mathrm{~mL}$ aqueous sample was placed into a $50 \mathrm{~mL}$ capped glass separatory funnel; $2 \mathrm{~mL}$ of HAc-NaAc buffer solution (pH 6) was added, followed by $1 \mathrm{~mL} \mathrm{CH}_{2} \mathrm{Cl}_{2}$ as extractant and $1 \mathrm{~mL} 4 \% \mathrm{NaBH}_{4}$ as derivative reagent. The funnel was capped immediately, shaken on an electric shaker for $5 \mathrm{~min}$ and, allowed to stand for $5 \mathrm{~min}$ for phase separation. Then the organic phase was separated and transferred into a capped glass vial which was placed in ice water to prevent the $\mathrm{CH}_{2} \mathrm{Cl}_{2}$ layer from vaporization. In case a preconcentration step was necessary, the organic extracts were taken into a flask and concentrated under decreased pressure by a rotatory evaporator. The volume of organic extract was condensed to $0.05-0.1 \mathrm{~mL}$. $1 \mu \mathrm{L}$ of the extract was injected into the $\mathrm{GC}$ for analysis. The calibration curve was constructed by plotting the peak height versus the amount of standard dioctyltin solutions, from which the concentrations of the aqueous samples could be calculated.

\subsection{Beverages}

Since some beverages contained emulsive organic materials, the extract was difficult to be separated from water in the separatory funnel, even after a long settling period. To minimize errors, $50 \mu \mathrm{L}$ $(1 \mu \mathrm{g} / \mathrm{mL}$ as $\mathrm{Sn})$ tetrabutyltin (TeBT) as internal standard was added to the crude beverage samples. After the first extracted organic phase was removed, $1 \mathrm{~mL}$ of additional $\mathrm{CH}_{2} \mathrm{Cl}_{2}$ was added into the separatory funnel, and shaken slightly; the organic layer was then separated. This step was repeated three times. The organic extracts were combined and concentrated to $0.05-0.1 \mathrm{~mL}$ by a rotatory evaporator. The content of organotin compounds was calculated by the internal standard method.

\section{Results and discussion}

\subsection{Derivatization}

The derivatization methods for organotin in GC analysis mainly include three procedures: alkylation by Grignard reagents [9-11], ethylation by sodium tetraethylborate
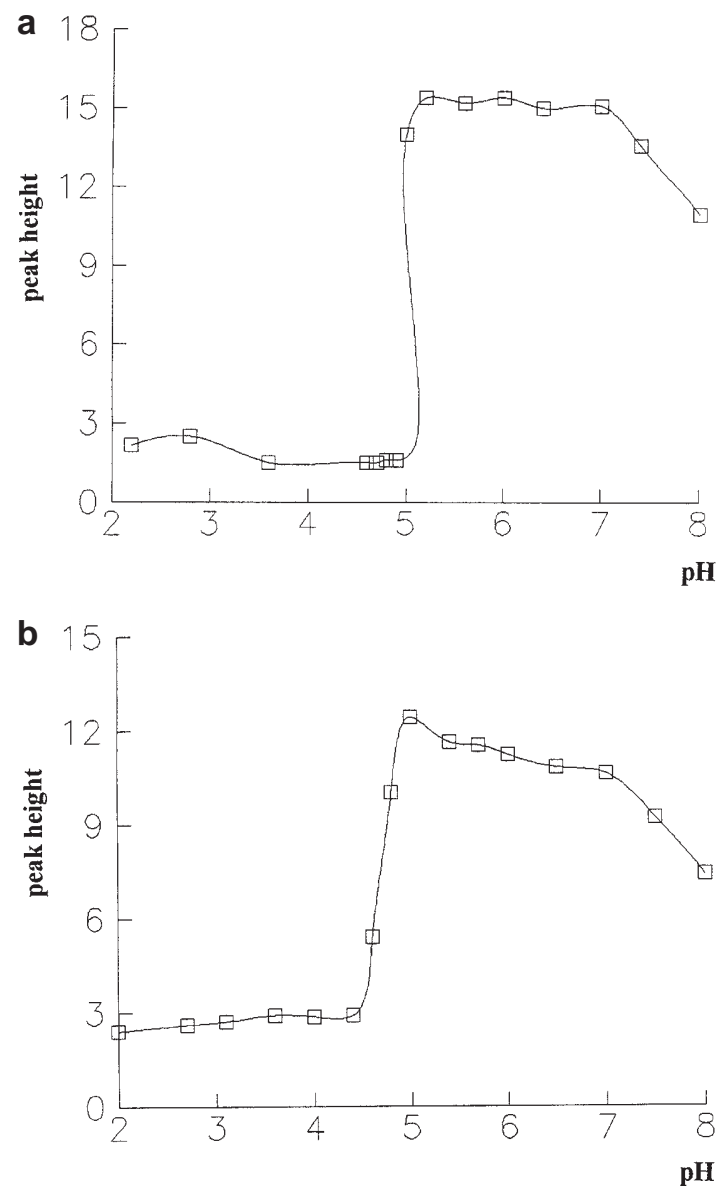

Fig. 1a, b Effect of $\mathrm{pH}$ on the efficiency of the derivatization of dioctyltin. a HAc-NaAc buffer system; b $\mathrm{Na}_{2} \mathrm{HPO}_{4}$-citric acid buffer system

$\left(\mathrm{NaBEt}_{4}\right)$ [12, 13] and hydride generation by sodium borohydride $\left(\mathrm{NaBH}_{4}\right)[14,15]$. Advantages of derivatization by $\mathrm{NaBH}_{4}$ compared with Grignard reaction and ethylation are that $\mathrm{NaBH}_{4}$ is less expensive, easier to handle and gives a high response. However, this procedure is greatly affected by the matrix, especially the $\mathrm{pH}$ of the solution. To optimize the $\mathrm{pH}$ range, volumes of $20 \mathrm{~mL}$ distilled water containing the same concentration of dioctyltin compound were mixed with $2 \mathrm{~mL}$ of HAc-NaAc of different $\mathrm{pH}$. The peak heights of dioctyltin dihydride $\left(\mathrm{Oc}_{2} \mathrm{SnH}_{2}\right)$ measured from different $\mathrm{pH}$ solutions are shown in Fig. 1 a. As the $\mathrm{pH}$ ranged from 2.2 to 4.8 , the peak height responses were obtained at low levels. The best responses were obtained in the $\mathrm{pH}$ range 5.20-7.50. To confirm this trend, we prepared another buffer solution by mixing appropriate amounts of $\mathrm{Na}_{2} \mathrm{HPO}_{4} \cdot 12 \mathrm{H}_{2} \mathrm{O}(1 \mathrm{M})$ with citric acid (1 M). As seen in Fig. $1 \mathrm{~b}$, the variation of peak height with $\mathrm{pH}$ gives a similar trend as in Fig. 1 a. These results are also quite agreeable with Andreae and Byrd's observation [16].

We have also examined the influence of the amount of $\mathrm{NaBH}_{4}$ and the extraction time, which are two factors affecting the yield of the derivatization reaction. The amount of $\mathrm{NaBH}_{4}$ was measured and the results are shown in Fig. 2. 


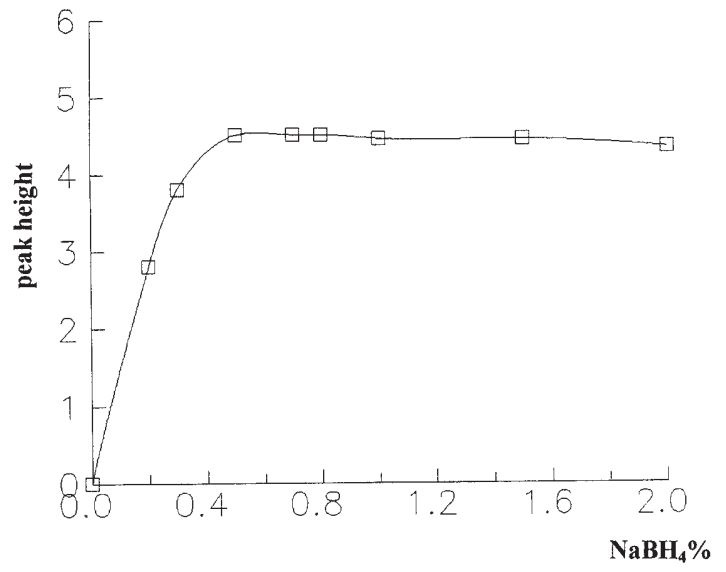

Fig. 2 Effect of the $\mathrm{NaBH}_{4}$ concentration on the efficiency of the derivatization of dioctyltin

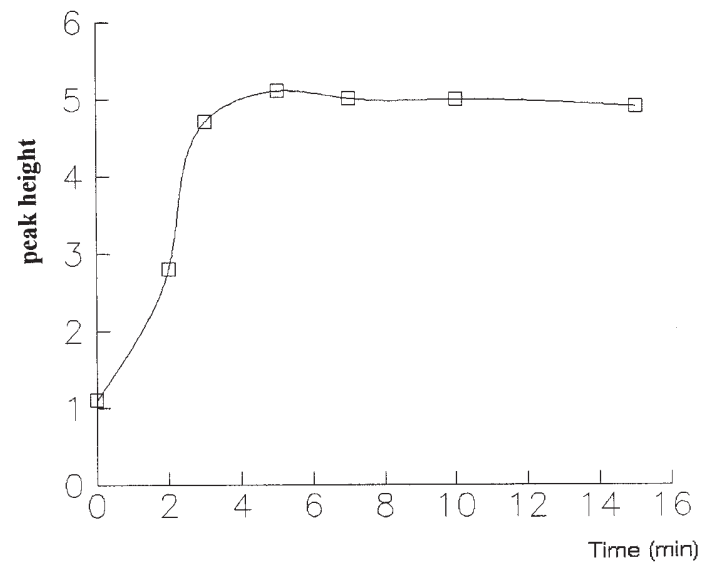

Fig. 3 Effect of the shaking time on the efficiency of the extraction of dioctyltin

The high recoveries show that the addition of $1 \mathrm{~mL} 4 \%$ $(\mathrm{w} / \mathrm{v}) \mathrm{NaBH}_{4}$ is sufficient even when some beverage samples contained large amount of organic matter. The extraction was performed by putting the separatory funnel on an electric shaker. Figure 3 shows that 5 min of extraction appeared to be sufficient.

\subsection{Separation and identification}

Under the conditions of column temperature programming and carefully adjusting the nitrogen flow rate, the dioctyltin compound can be baseline separated from butyltin species. Figure 4 depicts a chromatogram of all three derivatives. In order to confirm the dioctyltin hydride, an HPLC-electrospray-MS identification was carried out using a Fisons VG-platform mass spectrometer equipped with a Hewlett-Packard liquid chromatograph and an electrospray ionization source. The operation voltage of the ES capillary was $3.29 \mathrm{KV}$ and the $\mathrm{HV}$ lens was at $0.20 \mathrm{KV}$ throughout the whole measurement. Figure 5 shows the MS spectrum of $\mathrm{Oc}_{2} \mathrm{SnH}_{2}$. Based on the tin isotope of ${ }^{120} \mathrm{Sn}$, a typical fragmentation of $[\mathrm{M}-\mathrm{H}]^{-}$at 347
Fig. 4 Gas chromatogram of organotin standard. Peaks:

1. solvent; 2. tributyltin (0.6 ng as $\mathrm{Sn}) ; 3$. tetrabutyltin

(TeBT,0.5 $\mathrm{ng}$ as Sn); 4.

dioctyltin (DOT, $5 \mathrm{ng}$ as $\mathrm{Sn}$ )

can be observed, which revealed that hydrogen is easier to lose under ESI conditions than the octyl-group.

\subsection{Calibration and recovery}

The calibration curve was constructed by analyzing standard solutions containing different amounts of tributyltin and dioctyltin compounds. The correlation coefficients were 0.9998 for tributyltin and 0.9994 for dioctyltin, showing good linearity within the calibration ranges. In case condensation was necessary, tetrabutyltin (TeBT) was added as internal standard to ensure the accuracy of the measurement. To evaluate the recovery efficiency, spiked water samples and beverages were analyzed. The recoveries at spike levels of $0.1 \mathrm{ng}$ to $0.2 \mu \mathrm{g}$ (as $\mathrm{Sn}$ ) in different water and beverage samples were found to range from $87 \%$ to $107 \%$, which indicated that there were no serious interferences from the sample matrix.

\subsection{Precision and detection limits}

The precision of the method was determined by running five consecutive standard solutions containing $0.5 \mathrm{ng}$ of tetrabutyltin, $0.6 \mathrm{ng}$ of tributyltin and $5 \mathrm{ng}$ of dioctyltin. The coefficients of variation were $2.5 \%, 3.3 \%$ and $2 \%$, respectively. The detection limit was defined as the signal equal to three times the standard deviation $(3 \sigma)$ of the baseline noise. When $1 \mu \mathrm{L}$ of standard solution was injected into the GC, the detection limit for dioctyltin, tetrabutyltin and tributyltin compounds were $10 \mathrm{pg}, 0.3 \mathrm{pg}$ and $0.7 \mathrm{pg}$, respectively. It is obvious that the detection limit of dioctyltin decreased more than one-fold compared with tributyltin and tetrabutyltin; this is probably due to the fact that the dialkyltin compound is easily adsorbed and decomposed during the chromatographic process [3]. 
Sn-1

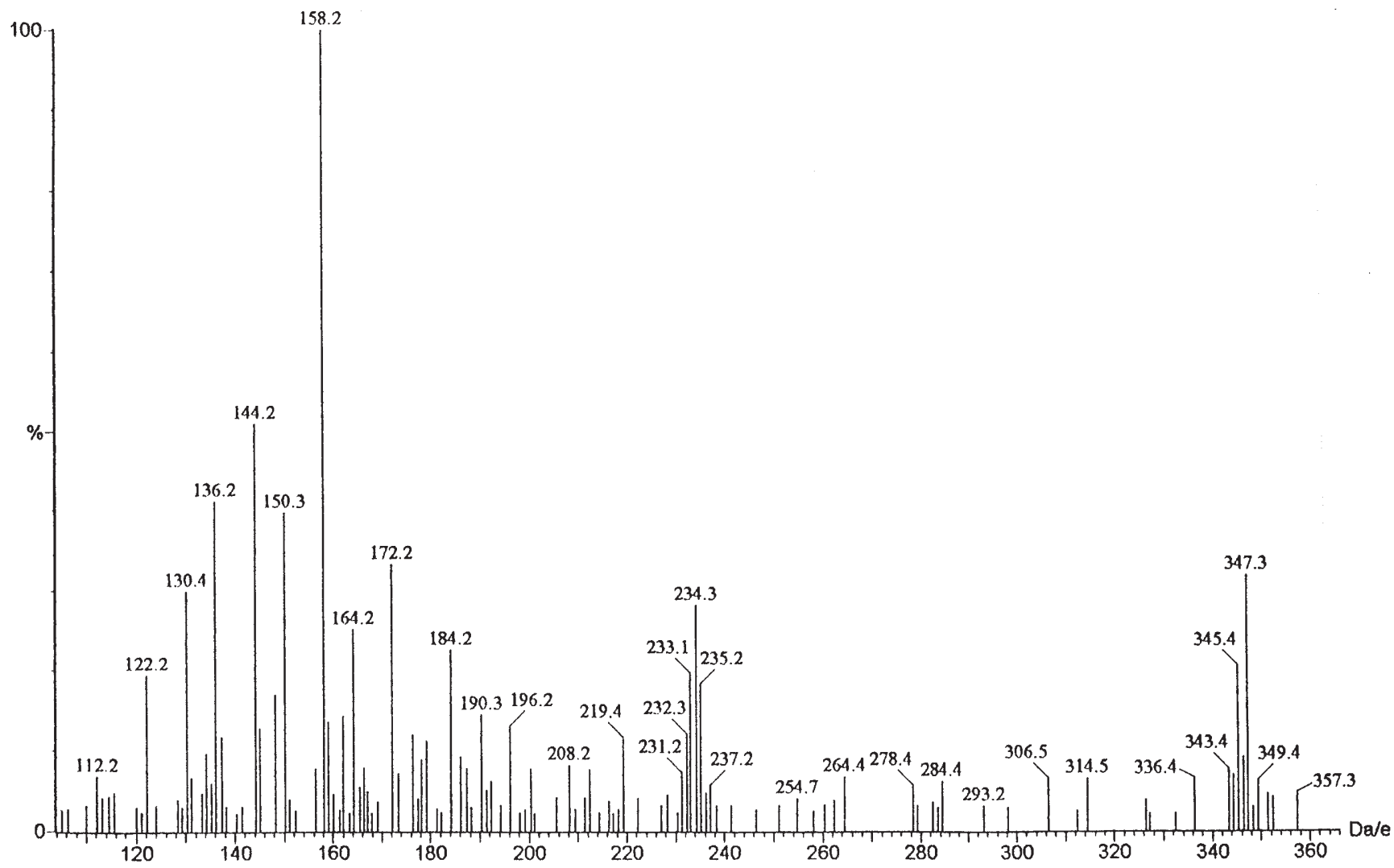

Fig.5 Mass spectrum of dioctyltin dihydride $\left(\mathrm{Oc}_{2} \mathrm{SnH}_{2}\right)$

Table 2 Dioctytin and tributyltin levels in different samples ${ }^{\mathrm{a}}$

\begin{tabular}{lcll}
\hline Sample & $\begin{array}{l}\text { Volume } \\
(\mathrm{mL})\end{array}$ & \multicolumn{2}{l}{ Measured $(\mathrm{ng} / \mathrm{mL} \text { as Sn })^{\mathrm{b}}$} \\
\cline { 3 - 4 } & & TBT & DOT \\
\hline Water 1 & 50 & ND & $1.43 \pm 0.10$ \\
Water 2 & 100 & ND & $0.74 \pm 0.04$ \\
Beverage & 20 & ND & $9.5 \pm 0.34$ \\
Waste water 1 & 10 & $0.47 \pm 0.02$ & $9.6 \pm 0.9^{\mathrm{c}}$ \\
Waste water 2 & 10 & $0.89 \pm 0.03$ & $5.2 \pm 0.4^{\mathrm{c}}$ \\
\hline
\end{tabular}

${ }^{a}$ five times replicated measurements

${ }^{\mathrm{b}}$ mean values \pm standard deviations

${ }^{\mathrm{c}}$ measured at $\mu \mathrm{g} / \mathrm{mL}$ as $\mathrm{Sn}$

\subsection{Sample analysis}

The application of this method to the determination of dioctyltin in real samples was demonstrated by analyzing a variety of samples including mineral water, waste water and beverages. The results are given in Table 2. Mineral water and beverages were bought from a local retail market; they had been in plastic bottles for more than one month. The waste water samples were collected from a local chemical factory. Since the concentration of dioctyltin in mineral water was very low, $50-100 \mathrm{~mL}$ volume of samples and condensation steps were necessary.

\section{Conclusions}

The proposed method using gas chromatography with flame photometric detection and quartz surface-induced tin emission offers certain advantages over the hitherto reported methods, i.e. simplicity, reliability and high sensitivity. In our investigations up to $9.5 \mathrm{ng} / \mathrm{mL}$ of dioctyltin was found in some beverages.

Acknowledgements This study was supported by the Chinese Academy of Sciences and the National Natural Science Foundation of China. G. B. Jiang is also grateful to the Working Foundation for selected scholars set by the CAS, the Research Foundation for Scholars set by the State Education Commission and the Technological Activity of Scholars in Non-educational Organization set by the Personnel Department for their support.

\section{References}

1. Forsyth DS, Weber D, Dalglish K (1993) Talanta 40:299-305 2. Donard OFX, Weber JH (1985) Environ Sci Technol 19:11041110

3. Yu TH, Arakawa Y (1983) J Chromatogr 258:189-197

4. Vainiotalo S, Hayri L (1990) J Chromatogr 523:273-280

5. Forsyth DS, Weber D, Barlow L (1992) Appl Organomet Chem 6:579-585

6. Yamada S, Fujii Y, Mikami E, Kawamura N, Hayakawa J (1993) J AOAC International 76:436-441

7. Jiang GB, Xu FZ (1996) Appl Organomet Chem 10:77-82

8. Jiang GB, Ceulemans M, Adams FC (1996) J Chromatogr 727:119-129 
9. Dirkx WMR, Adams FC (1994) Appl Organomet Chem 8:693701

10. Muller MD (1987) Anal Chem 59:617-623

11. Martin Landa I, Pablos F, Marr L (1991) Appl Organomet Chem 5:399

12. Michel P, Averty B (1991) Appl Organomet Chem 5:393-397
13. Ashby JR, Craig PJ (1991) Appl Organomet Chem 5:173-181

14. Braman RS, Tompkins MA (1979) Anal Chem 51:12-19

15. Sullivan JJ, Torkelson JD, Wekell MM, Hollingworth TA, Saxton WL, Miller GA (1988) Anal Chem 60:626-630

16. Andreae MO, Byrd JT (1984) Anal Chim Acta 156:147-157 